\title{
Unjuk Kerja Dan Perancangan poros Dan Bantalan pada Mesin diesel c22378hp dengan Menggunakan Dinamometer
}

\section{Working Performance And Design Of Axle And Bearings In C22378hp diesel Engine Using Dynamometer}

\author{
Erikson Marbun ${ }^{1{ }^{*}}$, Darianto ${ }^{2)}$, Bobby Umroh ${ }^{3)}$ \\ 1) Alumni Prodi Mesin, Fakultas Teknik, Universitas Medan Area, Indonesia \\ 2) Prodi Mesin, Fakultas Teknik, Universitas Medan Area, Indonesia
}

*Coresponding Email:

\begin{abstract}
Abstrak
Dinamometer adalah alat yang digunakan untuk mengukur prestasi sebuah mesin. Menurut tipenya dynamometer dibagi menjadi dinamometer transmisi,dynamometer penggerak dan dynamometer absorsi. Dinamometer tipe water brake adalah salah satu macam dari dinamometer absorsi. Dinamometer tipe water brake adalah bentuk lain sebuah pompa penyerap hidraulik. Konsep dynamometer tipe water brake sama dengan pompa sentrifugal, tetapi yang tidak efisien. Setelah diproduksi maka sebuah dynamometer perlu diuji untuk mengetahui spesifikasi dari dinamometer tersebut. Jarangnya penggunaan chassis dinamometer tipe water brake membuat sebagian besar masyarakat belum mengetahui cara dan langkah kerja dari alat ini, maka dibutuhkan sebuah panduan berupa buku petunjuk operasi yang berisi tentang penjelasan dan langkah-langkah pengukuran daya kendaraan dengan menggunakan chassis dinamometer tipe water brake. Dari hasil pengujian dapat diketahui bahwa semakin besar debit air yang dialirkan maka semakin besar daya yang diserap oleh dinamometer. Chassis dynamometer yang dikarakterisasi dapat digunakan untuk mengukur daya sesuai dengan trend linegrafiktorsi dan daya mesin uji yang digunakan yaitu $29.56 \mathrm{hp} / 2962 \mathrm{rpm}$ dan torsi hingga 76.03 N.m/2542 rpm. Daya yang terukur bukan merupakan daya maksimal yang mampu diserap oleh dinamometer, melainkan daya dari mesin yang diuji.
\end{abstract}

Kata Kunci : Dinamometer, torsi, daya, buku pedoman.

\begin{abstract}
Dynamometer is a tool used to measure the performance of a machine. According to the type the dynamometer is divided into the transmission dynamometer, the driving dynamometer and the absorber dynamometer. The dynamometer of the water brake type is one of a kind of absorption dynamometer. A water-brake dynamometer is another form of a hydraulic absorbent pump. The concept of a water brake dynamometer is the same as a centrifugal pump, but that is not efficient. Once produced then a dynamometer needs to be tested to determine the specifications of the dynamometer. Rarely the use of chassis dinamometer type water brake make most people do not know how and step of this tool, hence needed a guide in the form of operation manual which contains about explanation and measures of vehicle power by using chassis dinamometer type water brake. From the test results can be seen that the greater the flow of water flowing the greater the power absorbed by the dynamometer. Characterized dynamometer chassis can be used to measure power according to the linegraphic trend and the power of the test machine used is $29.56 \mathrm{hp} / 2962 \mathrm{rpm}$ and torque up to 76.03N.m / $2542 \mathrm{rpm}$. The measured power is not the maximum power capable of being absorbed by the dynamometer, but the power of the test
\end{abstract}


machine.

Keywords: Dinamometer, torque, power, manual book.

How to Cite: Marbun, E. Darianto. \& Bobby, U. (2017). Unjuk Kerja Dan Perancangan poros Dan Bantalan pada Mesin diesel c22378hp dengan Menggunakan Dinamometer. JMEMME (Journal of Mechanical Engineering, Manufactures, Materials and Energy). 1 (1): 10-18 


\section{PENDAHULUAN}

Pada umumnya suatu motor dapat diartikan sebagai suatu pesawat yang dapat mengubah energi tertentu menjadi energi gerak, sedangka nyang dimaksud dengan motor bakar yaitu mesin kalor dimana gas panas diperoleh dari proses pembakaran didalam mesin itu sendiri dan langsung dipakai melakukan kerja mekanis untuk menjalankan mesin tersebut[1].

Dalam seratus tahun sejarah perkembangannya sejak dibuat untuk pertama lebih kalinya motor bakar torak adalah penggerak mula yang ringan dan kompak, dewasa ini motor bakar torak mempunyai peran yang sangat penting dalam kehidupan manusia[1]. Hampir semua orang menikmati transportasi, manfaat penerangan, misalnya pada pertanian, dalam bidang industri dan sebagainya.

Pada dasarnya masalah yang akan dibahas dalam pengujian motor bakar adalah pembakaran dalam yang terdiri dari pengujian motor diesel empat langkah dengan beberapa pengamatan tentang karakteristik dan performa suatu mesin pada kondisi putaran konstan, throttle konstan dan beban konstan[2].

Mesin diesel merupakan sistem penggerak utama yang banyak digunakan baik untuk sistem transportasi maupun penggerak stasioner, dikenal sebagai jenis motor bakar yang mempunyai efisiensi tinggi[3]. Penggunaan mesin diesel berkembang pula dalam bidang otomotif antara lain untuk angkutan berat, traktor, bulldozer, pembangkit listrik didesa- desa, generator listrik darurat di rumah sakit, hotel dan sebagainya.

Alat uji torsi adalah suatu alatyang dirancang untuk mengukur seberapa gaya puntir yang dapat dilakukan saat melakukan pengujian dari suatu elemen mesin[4]. Caranya yaitu degnan memuntir batang uji terus menerus yang ditentukan dan putarannya harus searah.

Daya merupakan parameter yang menunjukkan kerja suatu mesin atau alat penghasil energi, misalnya mesin mobil atau motor[5]. Alat yang sudah dikenal untuk mengukur daya dari mesin motor atau mobil, untuk mencapai tujuan ini para pembuat mesin memerlukan peralatan ukur yang akurat untuk mengetahui berapa besar daya yang dihasilkan oleh kendaraan. Pada hal ini dinamometer adalah alat yang tepat untuk pekerjaan tersebut.

Bantalan adalah elemen mesin menumpu poros berbeban, sehingga putaran atau gerakan bolak-baliknya dapat berlangsung secara halus, aman, dan berumur panjang[6]. Bantalan harus cukup kokoh untuk memungkinkan poros serta 
elemen mesin lainnya bekerja dengan baik. Jika bantalan tidak berfungsi dengan baik maka prestasi seluruh system akan menurun atau tidak dapat bekerja secara semestinya.

Berdasarkan uraian diatas maka penulis tertarik untuk melakukan penelitian tentang „"Perencanaan Bantalan Untuk Alat Uji Torsi Pada Mesin Diesel C223 Dengan Daya 78HP”. Dengan adanya analisa ini diharapkan agar para pembaca, khususnya orang-orang yang terlibat dalam perencanaan dan perakitan dinamometer ini dapat mengetahui daya keluaran pada porosengkol mesin motor bakar, khususnya torsi yang dihasilkan dengan perubahan beban yang diberikan pada mekanisme pembebanan pada alat uji sehingga pemeriksaan pada konstruksi dinamometer ini dapat menghasilkan seperti yang diharapkan dan aman digunakan.

Dengan melihat kenyataan yang ada, bahwa pemilihan teknologi tepat guna, maka didalam penggunaan pemakaian dinamometer, setiap pengoperasian dari alat tersebut harus melaksanakan ketentuan-ketentuan yang berlaku pada undang-undang dan peraturannya serta standar yang ada untuk keselamatan kerjanya.

Poros adalah bagian dari elemen mesin yang berfungsi untuk mentransmisikan putaran dari suatu elemen ke elemen mesin lainnya[6]. Poros ditopang diatas dua atau lebih bantalan. Oleh karena itu perlu dikerjakan perhitungan poros pada perencanaan suatu bantalan. Selain mentransmisikan putaran, poros juga berfungsi mentransmisikan daya. Poros akanmengalami puntiran atau momen torsi. Dimana hal ini akan direncanakan sebuah poros untuk mentransmisikan daya pada sebuah mesin diesel C223 sebesar (P) 78 HP dan putaran mesin 6000 rpm.

$$
\text { Daya poros perancangan }
$$
dihitung dengan menggunakan persamaan 1. fc adalah faktor koreksi daya poros yang nilainya berkisar antara 1,0 - 1,5. P adalah daya nominal mesin yang dikonversikan ke satuan $\mathrm{kW}[5]$.

$$
P d=\text { fc. } P
$$

Momen torsi T yang dihasilkan akibat daya perancangan poros $\mathrm{Pd}$ dan putaran mesin $\mathrm{n}$ dihitung dengan menggunakan persamaan 2[5].

$$
\mathrm{T}=9,74.10^{5} \times \mathrm{Pd} / \mathrm{n}
$$

Bahanporos direncanakan dari bahan yang terbuat dari baja batang yang ditarik dingin dan di finish. Besarnya tegangan 
geser yang diizinkan $\tau_{\mathrm{a}}$ dihitung berdasar kekuatan tarik bahan $\sigma_{a}$, berdasarkan persamaan 3[5].

$$
\tau_{\mathrm{a}}=\frac{\sigma_{a}}{s f_{1} x s f_{2}}
$$

Diameter poros ds dipengaruhi oleh besarnya torsi $\mathrm{T}$ yang terjadi, faktor kejut $\mathrm{Kt}$, faktor lenturan $\mathrm{Cb}$, dan berbanding terbalik dengan tegangan geser izin $\tau_{a}$, yang dihitung menggunakan persamaan $4[6]$.

$$
\mathrm{ds}=\left[\frac{5,1}{\tau_{a}} K t \cdot C b \cdot T\right]^{1 / 3}
$$

Perancangan bantalan dalam penelitian ini didasarkan pada hubungan antara diameter luar dan dalam bantalan (D/d). Hubungan ini memenuhi persamaan $5[5]$.

$$
\mathrm{D} / \mathrm{d}=\sqrt{\frac{1}{5,1} \chi \frac{\sigma_{a}}{P_{a}}}
$$

Tujuan penelitian ini ialah mendapatkan unjuk kerja mesin diesel jenis C233 berkapasitas $78 \mathrm{HP}$, dan perancangan ukuran poros dan bantalan mesin dengan menggunakan alat ukur dinamometer. Sebelum pengukuran dan perhitungan, langkah pertama yang dikerjakan ialah membangun alat uji yang sesuai untuk keperluan penelitian. Oleh karena itu, dalam laporan ini akandijelaskan juga langkah-langkah penelitian dan rancang bangun serta unjuk kerjaalat uji tersebut.

\section{METODE PENELITIAN}

Penelitian perencanaan poros dan bantalan ini dikerjakan di Laboratorium Prestasi Mesin, Fakultas Teknik, Jurusan Teknik Mesin, Universitas Medan Area. Penelitian ini berlangsung selama 6 (enam) bulan dengan alur penelitian diperlihatkan pada gambar 1 .

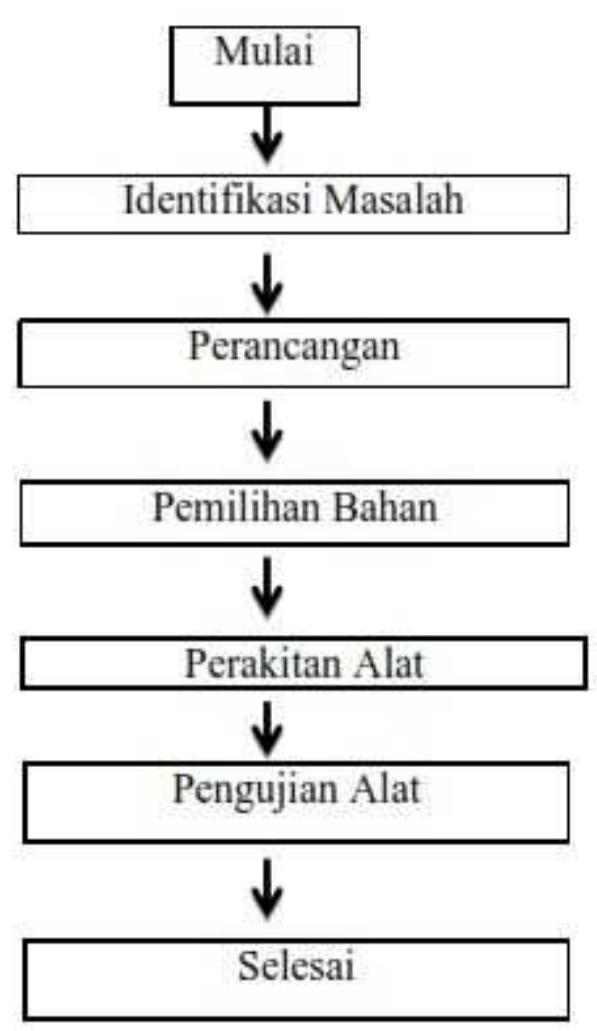

Gambar 1. Diagram alir penelitian

Uraian tahapan yang dilakukan dalam penelitian ini adalah sebagai berikut: 


\section{Membuat desain perencanaan} (gambar kerja).

Sebelum melakukan pembuatan dan perencanaan bantalan untuk dinamometer pada mesin diesel C223, peneliti harus bisa mendesain gambar sketsa dari sebuah dinamometer, agar lebih memudahkan dalam proses pembuatannya.

\section{Kesiapan alat dan bahan}

Setelah perencanaan gambar kerja selesai. Langkah selanjutnya adalah menyiapkan alat dan bahan untuk mendukung proses perakitan dan penggujian alat agar dapat terlaksana dengan baik.Dalam penelitian ini, alat dan bahan yang digunakan adalah: (a)Satu unit mesin diesel C 223 Daya 78 HP. (b)Satu buah poros penghubung mesin dengan mekanisme pengujian. (c)Bantalan poros penghubung. (d)Satu unit mekanisme pengujian. (e)Dudukan beban uji dan beban uji. (f)Drum brake. (g)Tachometer. (h)Alat pembebanan. (i)Gelas ukur. (j)Stopwatch.

\section{Proses perakitan}

Setelah alat dan bahan dipersiapkan, selanjutnya adalah melakukan proses perakitan komponen menjadi suatu mesin yang utuh. Dalam proses perakitan hal yang harus diperhatikan adalah memperhatikan antara satu komponen dengan komponen lainnya agar tidak terjadi kesalahan dalam proses perakitan.

\section{Pemeriksaan Mekanik}

Setelah perakitan selesai kemudian dilakukan pemeriksaan seperti pada mekanisme rem dan fluida silinder rem agar pada saat percobaan sesuai dengan hasil yang diharapkan.

\section{Pengujian kinerja motor diesel}

Setelah proses perakitan semua komponen telah selesai. Maka selanjutnya adalah proses pengujian. Dalam proses pengujian harus diperhatikan semua datadata yang sudah dikumpulkan, apakah data-data sesuai dengan yang diinginkan atau tidak.

\section{Pengumpulan data.}

Tahap pengambilan data dapat dilaksanakan setelah seluruh tahap persiapan selesai, dalam bagian ini penulis mengumpulkan data dari lapangan pada saat pengujian mesin dihidupkan sampai pengukuran torsi yang diukur pada alat dinamometer untuk jadi bahan analisa di bab berikutnya.

\section{Analisa data.}

Dalam hal ini penulis menganalisa pengujian yang dilakukan dari percobaan pengujian dinamometer setelah datanya sudah terkumpul, Data yang dipakai dalam penelitian ini merupakan data sekunder dari lapangan, adapun analisa tersebut meliputi : (a)Beban Pengereman (N). (b)Putaran Poros (rpm). (c)Kekuatan Konstruksi (MPa). (d)Keselamatan Kerja 


\section{HASIL DAN PEMBAHASAN}

Susunan motor bakar diesel C 233 berkapasitas 78 HP yang telah dirancang dan dibangun diperlihatkan pada gambar 2.

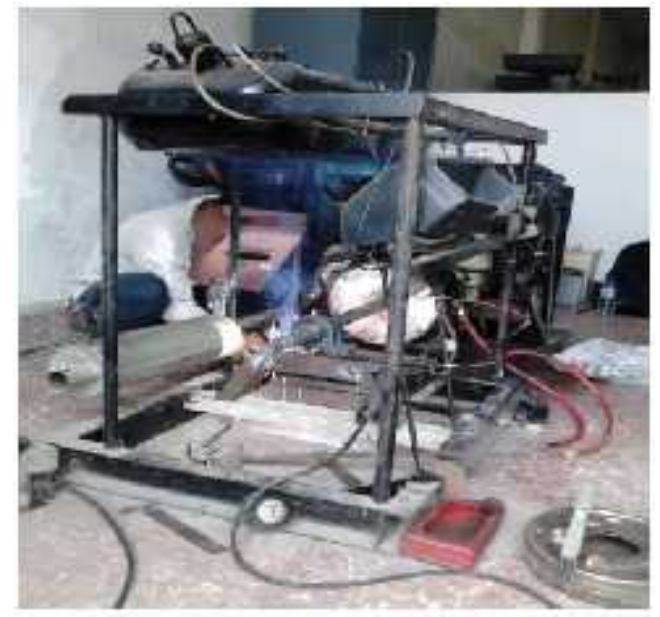

Gambar 2. Susunan alat uji mesin diesel C 23378 HP

Pemasangan alat dinamometer untuk mengukur putaran dan konsumsi bahan bakar selama pengujian berlangsung diperlihatkan pada gambar 3.

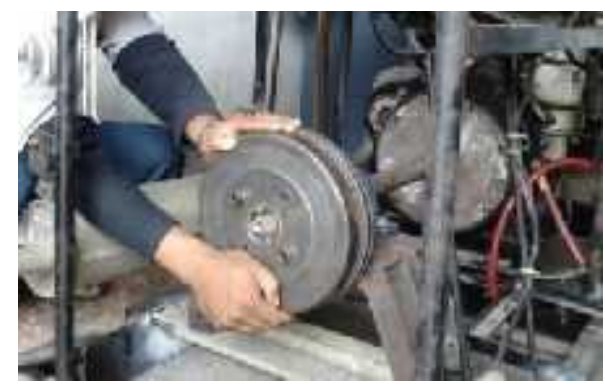

Gambar 3. Pemasangan alat dinamometer

Data hasil pengujian unjuk kerja mesin diperlihatkan pada gambar 4 dalam bentuk grafik hubungan antara putaran mesin (n) dan konsumsi bahan bakar (v) akibat variasi bebanbeban kerja mesin yang diberikan.

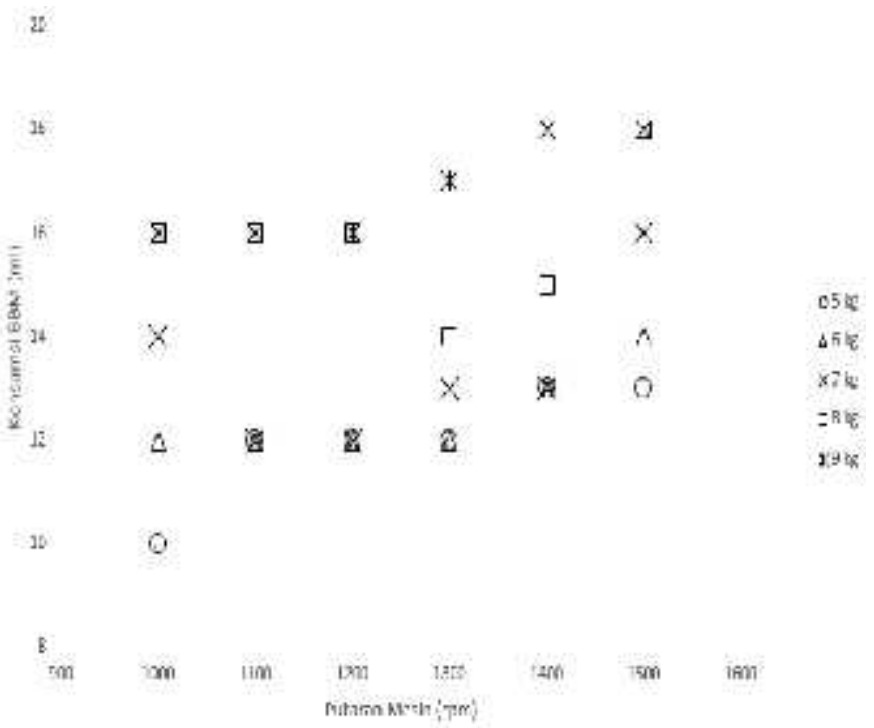

Gambar 4. Unjuk kerja mesin berdasarkan putaran dan beban kerja

Berdasarkan hasil uji unjuk kerja mesin seperti diperlihatkan pada gambar 4, terlihat bahwa semakin tinggi putaran mesin, maka konsumsi bahan bakar juga akan meningkat. Pada putaran mesin antara 1000 hingga $1200 \mathrm{rpm}$, konsumsi bahan bakar tidak terlihat perbedaan yang signifikan. Penambahan beban kerja mesin juga tidak memperlihatkan adanya perubahan konsumsi bahan bakar pada jangkauan putaran mesin tersebut. Pada putaran mesin diatas $1200 \mathrm{rpm}$, konsumsi bahan bakar meningkat sebesar 10 - 20\% dari sebelumnya. Akan tetapi stabil kembali pada putaran 1400 hingga 1500 rpm.

Besarnya daya perancangan poros yang dihitung dengan menggunakan 
persamaan 1 ialah sebesar 69,82 kW, dengan terlebih dahulu mengubah daya nominal 78 HP menjadi 58,12 kW (1 HP = 0,746 kW). Besarnya torsi yang terjadi dihitung dengan menggunakan persamaan 2, yaitu sebesar 11335 kg.mm. Dalam rancangan dinamomter ini diambil bahan poros S45C-D dengan kekuatan tarik $\sigma_{a}$ sebesar $60 \mathrm{~kg} / \mathrm{mm}^{2}$. Besarnya tegangan geser izin dihitung dengan menggunakan persamaan 3, yaitu sebesar $5 \mathrm{~kg} / \mathrm{mm}^{2}$. Dengan demikian besarnya diameter poros yang dirancang dapat dihitung dengna menggunakan persamaan 4 , yaitu ds = 38,47 mm. Untuk alasan keamanan konstruksi, maka diameter poros diambil sebesar $40 \mathrm{~mm}$. Periksa kembali tegangan geser yang terjadi dengan menggunakan persamaan 4 untuk memastikan tegangan geser yang terjadi $\leq$ tegangan geser izin. Diperoleh tegangan geser yang terjadi ialah 2,14 $\mathrm{kg} / \mathrm{mm}^{2}$. Dengan demikian ukuran diameter poros yang diambil dapat dinyatakan aman dalam pemakaiannya.

Berdasarkan ukuran diameter poros yang telah dihitung tersebut, maka ukuran bantalan yang digunakan dapat ditentukan dengan menggunakan persamaan 5. Diperoleh ukuran diameter luar bantalan sebesar 66 mm. Berdasarkan tabel karakteristik bantalan [1], jenis bantalan yang sesuai untuk keperluan ini ialah jenis FYH 6006 dengan ukuran diameter dalam $40 \mathrm{~mm}$, diameter luar 80 $\mathrm{mm}$, dan lebar $18 \mathrm{~mm}$.

\section{SIMPULAN}

Berdasarkan hasil uji unjuk kerja mesin yang telah dilakukan diperoleh bahwa karakteristik mesin diesel C 23378 HP ini memiliki kecenderungan konsumsi bahan bakar yang cukup stabil dalam jangkauan-jangkauan putaran mesin tertentu meski diberikan penambahan beban. Pada jangkauan putaran mesin 1000 - 1200 rpm, konsumsi bahan bakarnya adalah $12 \mathrm{ml}$ pada jangkauan beban 5 hingga $7 \mathrm{~kg}$, dan $16 \mathrm{ml}$ pada jangkauan beban 8 hingga $9 \mathrm{~kg}$.

Ukuran diameter poros mesin yang digunakan ialah $40 \mathrm{~mm}$ dengan bahan poros S45C-D. Pengambilan ukuran ini berdasarkan analisa yang telah dikerjakan, dimana tegangan geser yang terjadi yaitu sebesar 2,14 kg/mm² masih jauh lebih kecil dari tegangan geser bahan, yaitu 5 $\mathrm{kg} / \mathrm{mm}^{2}$. Berdasarkan data-data analisa poros, maka diperoleh jenis bantalan yang sesuai untuk mesin ini ialah jenis FYH 6006 dengan ukuran diameter dalam 40 $\mathrm{mm}$, diameter luar $80 \mathrm{~mm}$, dan lebar bantalan $18 \mathrm{~mm}$. 
Erikson Marbun,Darianto, Bobby Umroh, Unjuk Kerja Dan Perancangan poros Dan Bantalan pada Mesin diesel...

\section{DAFTAR PUSTAKA}

[1] W. Arismunandar, Penggerak Mula Motor Bakar Torak, Bandung: ITB Bandung, 2002.

[2] A. Wiranto and K. Tsuda, Motor Diesel Putaran Tinggi, Jakarta: PT Pradnya Paramita, 2010.

[3] V. L. Maleev and B. Priambodo, Operasi dan Pemeliharaan Mesin Diesel, Jakarta: Erlangga, 2006.

[4] A. Zainun, Elemen Mesin I, Bandung: PT Refika Aditama, 2005.

[5] Sularso and K. Suga, Dasar Perencanaan dan Pemilihan Elemen Mesin, Bandung: PT Pradnya Paramita, 2002.

[6] J. E. Shigley, Mechanical Engineering Design, New York: Mc. Graw-Hill, 2006. 